\title{
Esthetic Rehabilitation: A Case Report
}

\author{
Dr. Nishanth $\mathbf{M}^{1}$, Dr. S Anilkumar ${ }^{2}$, DR. Rajesh $C^{3}$, DR Geethu $R^{4}$, Dr Indu $V^{5}$ \\ ${ }^{1}$ Junior Resident, Dept of Prosthodontics, Govt Dental College , Kottayam, \\ ${ }^{2}$ Professor and Head Department of Prosthodontics, Govt Dental college Kottayam \\ ${ }^{3}$ Assistant Professor, Govt Dental college, Kottayam. \\ ${ }^{4}$ Senior Resident, Dept of Prosthodontics, Govt Dental College, Alappuzha. \\ ${ }^{5}$ Junior Resident, Dept of periodontics, Govt Dental College, Kottayam
}

\begin{abstract}
One of the major focus of current restorative and prosthodontic dental treatment is on restoration of esthetics. For a treatment procedure to be successful, good communication with the patient to understand his/her functional and esthetic expectation is essential. During treatment planning phase, use of a diagnostic anatomic wax up helps the dentist to effectively communicate the final esthetic result to the patient. Esthetic pre evaluative temporaries prepared from the anatomic wax mock-up not only allows the clinician and patient to assess the form and contour of future restorations to be place but alsohelps to evaluate its effect on lip posture, smile line, and function. This case report describes a multidisciplinary approach for esthetic rehabilitation of a patient previously treated with faulty maxillary anterior fixed dental Prosthesis (FDP).
\end{abstract}

Keywords: esthetic rehabilitation ,clear addition silicone impression material,preevaluative tempoararies

\section{Introduction}

Dentistry has undergone unprecedented revolution over the past 30 years, not only due to introduction of newer materials and techniques, but also with regard to gathering scientific evidence supporting their clinical application. Metal ceramics have been the restorative material of choice for nearly three decades due to their popularity for predictable performance and reasonable esthetics. Despite their success, demand for improved esthetics has led to introduction of all ceramic restoration ${ }^{1,2}$. As ceramic material science evolve and as patient's demand for esthetic restoration increases, practitioners are forced to keep abreast with the science to meet the demands of the patient ${ }^{3}$. According to several studies, it is especially the smile that influences the appearance since a beautiful smile seems to convey serenity, safety, and success in the beholder ${ }^{4}$.Patients who seek dental treatment require, in addition to functional improvement, an outcome that meets their esthetic demand also, in order to obtain a natural smile and beautiful teeth ${ }^{5}$.

Maxillary anterior FPD's provide an exciting challenge to the artistic and technical abilities of the dentist, which and call upon their knowledge on smile design principles of proportion, symmetry, harmony and tooth morphology. Smile rejuvenation can positively impact a patient's selfesteem and emotional health through the improved appearance ${ }^{6}$.

Major reason for aesthetic dental treatment is the desire to have an esthetically pleasing appearance and thus, the success of a treatment can be effectively evaluated by patient satisfaction. Understanding patient's expectations before starting any esthetic restorative treatment is absolutely essential for the success. Easiest and perhaps the most effective method to communicate treatment outcome with the patient is to, try in a three dimensional mock up of the final prosthesis. It would be an added advantage if the mock up could be used to evaluate the functional status of the final prosthesis as well. Esthetic and functional assessment include evaluation of lip posture, relationship of the smile line with lower lip, occlusion, and phonetics ${ }^{7}$.

This case report presents a patient who demanded replacement of the existing faulty restoration and correction of facial profile, for cosmetic reasons. A novel technique for fabrication of anterior restorative temporary try in temporary try in prosthesis used to evaluate the treatment outcome is described here.

\section{Case Report}

A female patient aged 30 years reported to the Dept of Prosthodontics, Govt Dental College Kottayam with chief complaint of unesthetic anterior FDP received elsewhere . She complained of proclined and bulky restoration affecting her appearance. The clinical examination revealed splinted porcelain fused to metal FDP from 13 to 23 . Besides a convex profile with pronounced chin, the patient also exhibited bilateral gummy smile of 3 to $4 \mathrm{~mm}$ in the lateral incisor and canine regions bilaterally ( Figure $1 \& 2$ ). The medical history was non contributory.

The occlusion was analyzed preoperatively, both clinically and with the aid of mounted models on a semi-adjustable articulator. Radiographic examination showed multiunit joined Porecelain fused to metal (PFM) crowns on vital maxillary anterior teeth. After examination and data collection a treatment plan was charted out with the consent of patient for replacement of the splinted crowns. Since the vital abutment teeth had unfavourable buccal inclination intentional Root Canal (RCT) was planned for 11,12,13,21,22 and 23. Further surgical crown lengthening of these teeth were planned to compensate the gummy smile. In order to verify the outcome of interventional procedures including tooth preparation and surgical crown lengthening, 


\section{International Journal of Science and Research (IJSR) \\ ISSN (Online): 2319-7064}

Index Copernicus Value (2015): 78.96 | Impact Factor (2015): 6.391

it was decided to fabricate a template of the final prosthesis. High lip line was assessed and transferred on to the stone cast to determine the desired gingival level at the time of mock surgery. After mounting the diagnostic casts on a semi adjustable articulator a mock tooth preparation and crown lengthening procedure up to the desired level was completed. A wax up using tooth colored wax to replicate the contours of the final prosthesis was then done on the prepared cast (Figure 3 ).

An impression of the diagnostic cast with the mock wax up was made using irreversible hydrocolloid impression material to fabricate a stone model. A surgical splint in autopolymerizing acrylic was fabricated on this cast so as to provide a guide for crown lengthening procedure (Figure4\&5). On completion of surgical crown lengthening, autopolymerizing acrylic resin temporary crowns fabricated according to the diagnostic wax up was cemented with non eugenol (3M ESPE RelyX ${ }^{\mathrm{TM}}$ Temp NE LOT 611231) temporary cement (Figure 6). Patient was recalled after 6 weeks for modification of tooth preparation and fabrication of the definitive prosthesis. On removal of temporary crown it was noted that complete healing of the surgical site had occurred.

At this stage existing tooth preparation was modified to receive an all ceramic restoration.

New maxillary and mandibular impressions were made in addition silicone. Face bow transfer was done and the casts were mounted in a semi adjustable articulator. A new diagnostic wax up was prepared and a putty index of this wax up was made using clear addition silicone impression material (MEMOSIL ${ }^{\circledR} 2$ Heraeus Kulzer GmbH, LOT 415059) (Figure 7). The putty index was filled with composite material and placed over the prepared tooth and was light cured for 20 seconds (Figure 8). The transparency of the impression material enabled the use of light cured restoration. This temporary composite mock up was tried in the mouth and on approval by the patient it was cemented with temporary cement. The patient returned back to her daily social activities with the composite temporary for better esthetic evaluation by her relatives and friends. After 1 week when the patient was recalled she complained of long anterior teeth. The temporary was adjusted intra orally and the patient was recalled after 1 week. At this recall appointment the patient was esthetically satisfied with her new look. An impression over the temporary was then made in irreversible hydrocolloid impression material to fabricate a stone cast which served as a guide during the fabrication of final zirconia crowns.

The final maxillary arch impression was made with a combination of heavy and light viscosity polyvinyl siloxane after gingival retraction with magic foam cord (figure 9\&10). Impression of the opposing arch was also made with irreversible hydrocolloid followed by an interocclussal record at the maximum intercuspation. The Shade was selected using a shade guide (VITA 3D MASTER). The composite temporary was then recemented with non eugenol temporary cement. Zirconia frame work of the final prosthesis was tried intra orally to evaluate the fit. Finally the finished zirconia crowns were cemented with glassionomer cement (Figure 11).

\section{Discussion}

Correction of dental esthetic inconsistencies need careful evaluation, planning and multidisciplinary approach.The size, form and appearance of maxillary anterior teeth is important not only for dental esthetics but also for facial esthetics. Aesthetics of a smile is determined by the characteristics of teeth and harmonious architecture of the gingival tissues. The goal is to restore maxillary anterior teeth in harmony with adjacent tissues and improve the facial appearance ${ }^{8 .}$

In the presented case anatomic diagnostic mock-up helped to visualize the alterations needed to achieve a pleasing smile and thus aided in treatment planning. The diagnostic wax mock up was transferred to patient's mouth to fabricate the preevaluative tempoararies using transparent addition silicone index and light cure composite material. This enabled the clinician to effectively communicate the final esthetic out come to the pateint . With the preevaluative temporaries in place, the esthetics, the phonetics and even the occlusion is evaluated and necessary corrections are made ${ }^{9,10}$. Anatomic wax-up can also be used in the fabrication of a gingival-contour surgical stent, which is used during the crown-lengthening procedure to visualize the proposed final gingival contours at surgery ${ }^{11}$.

As opaque metal substructure causes undesirable light reflection, ceramics are considered the best in mimicking natural tooth appearance. This material provides a deep translucency similar to natural teeth allowing more light to enter and scatter. Recently, among the all ceramic systems, Zirconia based ceramics have become topic of interest in the field of prosthodontics for both, its mechanical properties which are very similar to those of metal and colour which is similar to natural tooth ${ }^{12}$.

\section{Conclusion}

The use of all-ceramic Fixed Dental Prosthesis (FDP) instead of conventional full or partial-coverage metalceramic FDP's in suitable cases would improve the esthetics of the patient. Anatomic wax mock-up is an important tool during the phase of treatment planning. It enables the dentist, to effectively communicate the final esthetic result of treatment to the patient. Esthetic preevaluative temporaries prepared from the anatomic wax mock-up facilitate the clinician and the patient to assess the form and contour of future restorations to be placed. In the clinical case presented, zirconia FDP's fabricated after evaluation of esthetic temporaries has permitted the rehabilitation of teeth with excellent esthetic results. Whereas, the periodontal surgery utilizing temporaries as a guide have helped to balance the soft tissue profile and thus to provide a natural, harmonic, and pleasant smile. A novel technique for fabrication of esthetic temporaries and its evaluation is discussed which essentially help in the fabrication of final prosthesis. 


\section{International Journal of Science and Research (IJSR) \\ ISSN (Online): 2319-7064}

Index Copernicus Value (2015): 78.96 | Impact Factor (2015): 6.391

\section{References}

[1] Kelly $\mathrm{JR}^{1}$,Benetti $\mathrm{p}$ Ceramic materials in dentistry: historical evolution and current practice. Aust Dent J. 2011 Jun;56 Suppl 1:84-96. doi: 10.1111/j.18347819.2010 .01299$.

[2] Hatai Y Extreme masking: achieving predictable outcomes in challenging situations with lithium disilicate bonded restorations. Int J Esthet Dent. 2014 Summer;9(2):206-22.

[3] Spear F, Holloway J. Which all ceramic system is optimal for anterior esthetics? J Am Dent Assoc 2008; 139: 19-24.

[4] S.Malkinsons, T. C.Waldrop, J. C.Gunsolley, S. K. Lanning, and R. Sabatini, "Theeffect of esthetic crown lengthening on perceptions of a patient's attractiveness, friendliness, trustworthiness, intelligence and selfconfidence," Journal of Periodontology, vol.84, no. 8, pp. 1126-1133, 2013.

[5] N. Sharma, S. F.Rosenstiel, H. W. Fields, and F. M. Beck, "Smilecharacterization by U.S. white, U.S. Asian Indian, and Indian populations," Journal of Prosthetic Dentistry, vol. 107, no. 5, pp. 327-335, 2012

[6] Sharma a k, Bhanot r, Bansal p, Kapoor D Aesthetic Management Of Proclined Maxillary Central Incisors With All-Ceramic Crowns : A Case Report

[7] Rozafa Dragusha, PhD Proc. Private Practice, Albania Djemal Ibraimi, CDT Laboratory Owner, Switzerland Mock-up: An Aid in the Different Steps in Aesthetic Dental Treatment. doi: 10.19044/esj.2016.v12n6p290

[8] Vishwas Anjum and Shiromany Aseem From NonEsthetic to Esthetic Rehabilitation: A Case ReportAsian Journal of Oral Health \& Allied Sciences 2012, Volume 2, Issue 2

[9] Gürel G. Discovering the artist inside: A three-step approach to predictable aesthetic smile designs, Part I. Dent Today 2013;32:74, 76-8.

[10] Gürel G. Discovering the artist inside: A three-step approach to predictable aesthetic smile designs, part 2 . Dent Today 2013;32:126, 128-31.

[11] Doundoulakis JH, Melnick CS. A strategy for correcting poor anterior aesthetics. A case study. Dent Today 2004;23:96-9.

[12] Nelson R.F.A.Slva,Irena Sailer,Yu Zhang, Paulo G.Coelho, Petra C.Guess, Anja Zembic, Ralf J.Kohal. Performance of Zirconia for dental healthcare.Materials 2010;3:863-896

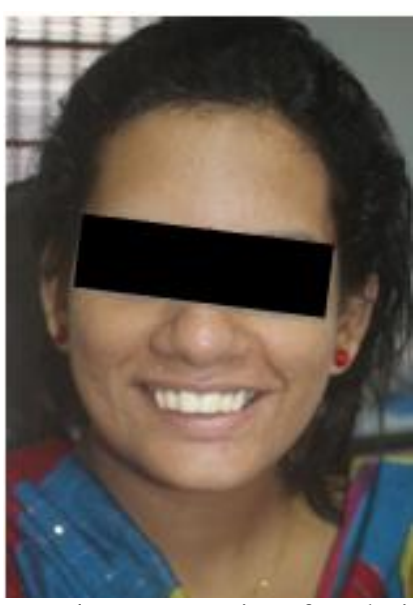

Figure 1: Preoperative frotal view

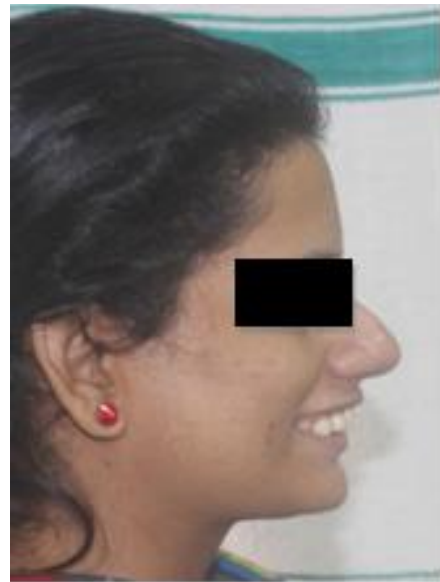

Figure 2: Preoperative profile view

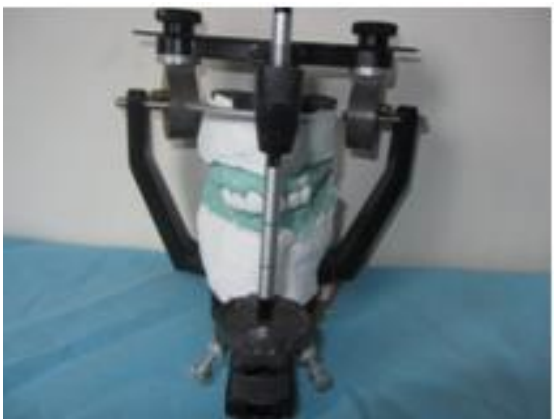

Figure 3: Diagnostic wax up

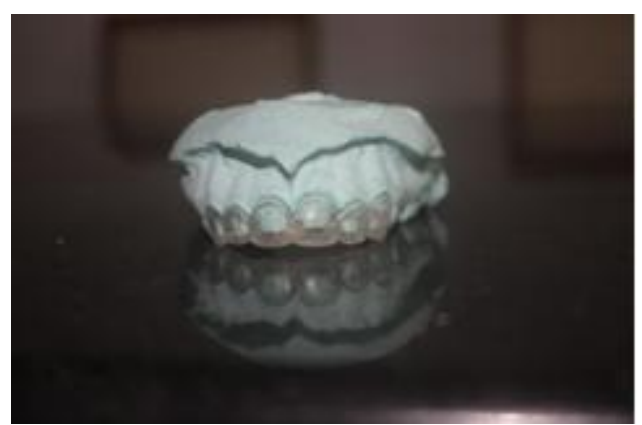

Figure 4: Stone model with surgical stent 


\section{International Journal of Science and Research (IJSR)}

ISSN (Online): 2319-7064

Index Copernicus Value (2015): 78.96 | Impact Factor (2015): 6.391

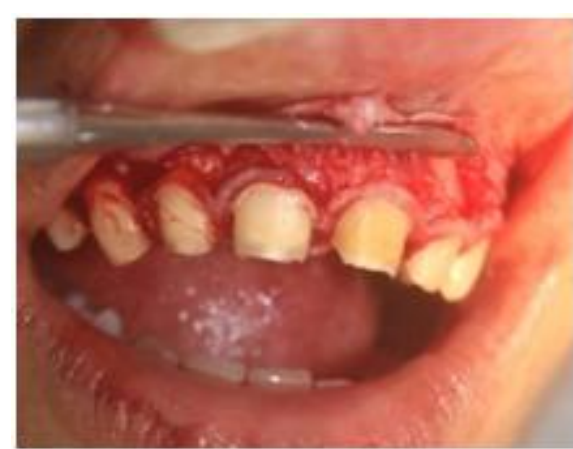

Figure 5: Surgical crown lengthening

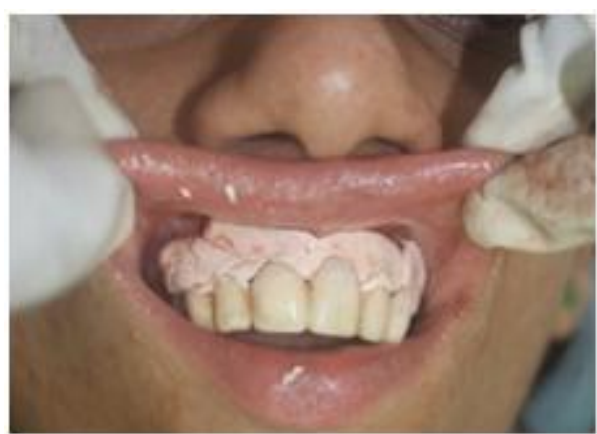

Figure 6: Acrylic temporary in place

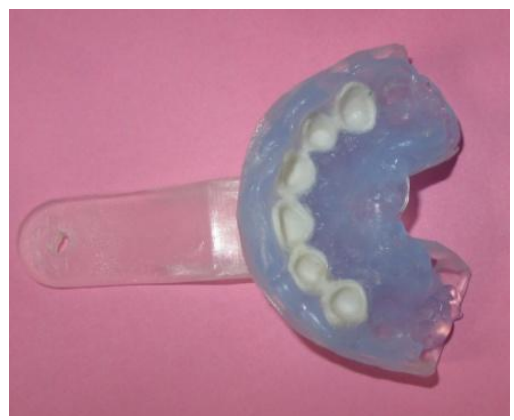

Figure 7: Putty index of the new wax mock up

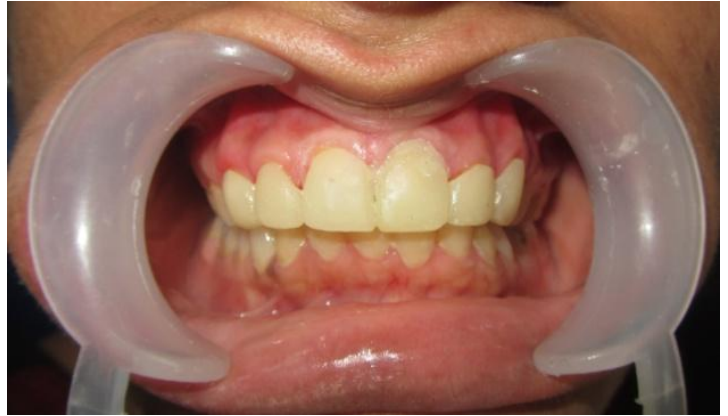

Figure 8: Preevaluative temporary

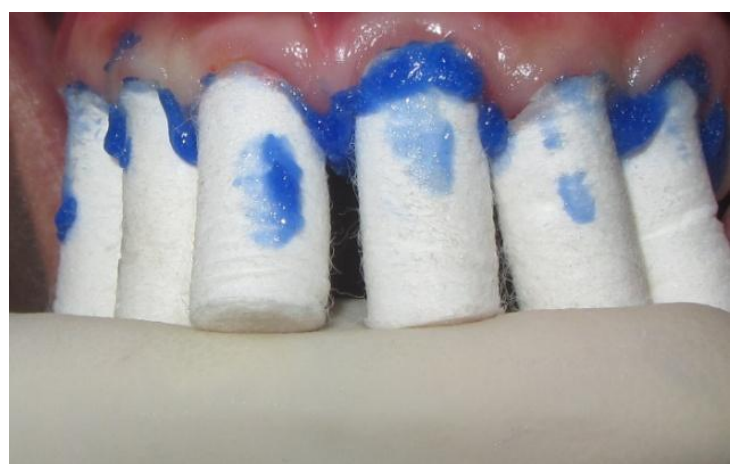

Figure 9: Gingival retraction using Magic foam cord

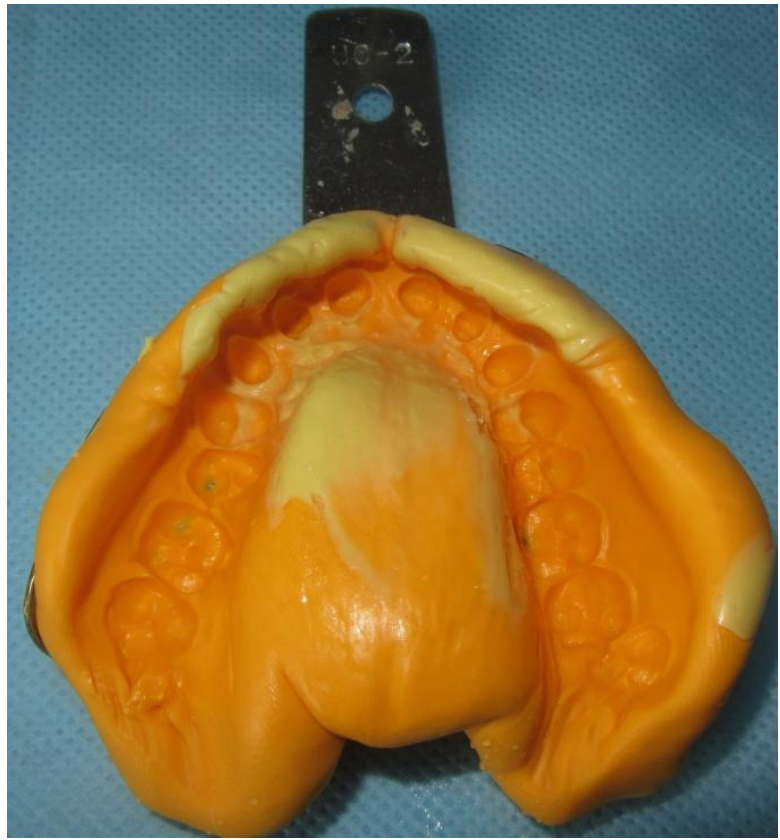

Figure 10: Addition silicone impression

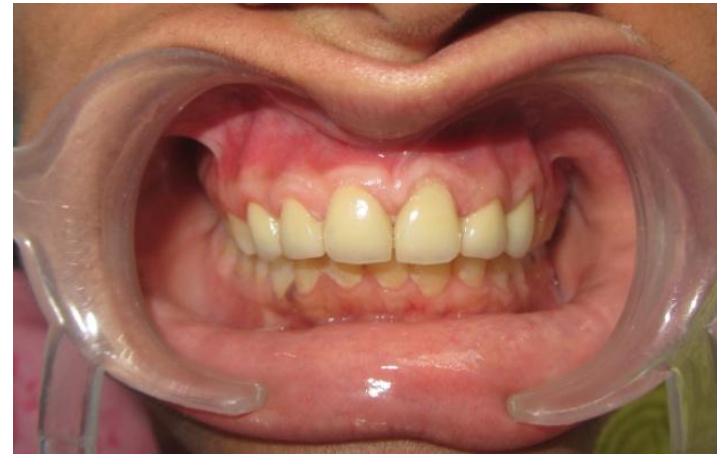

Figure 11: Final ZIrconia crowns 


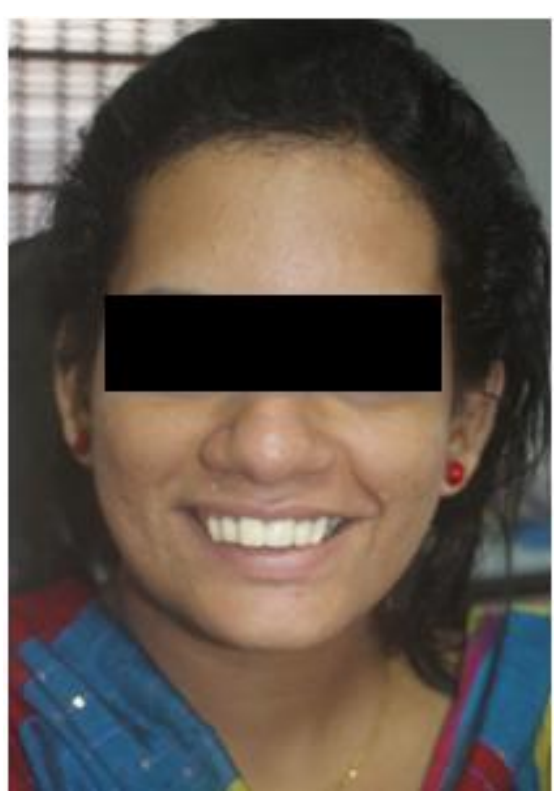

Figure 12: Before

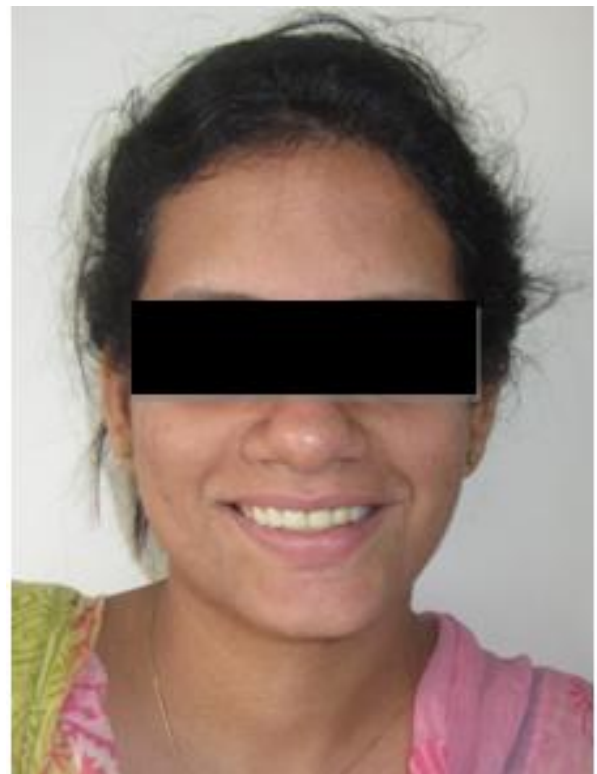

Figure 13: After

Volume 6 Issue 7, July 2017 www.ijsr.net 